\title{
FIVE CASES OF STRICTURE OF THE RECTUM *
}

\author{
By GEORGE M. GRAY, M.D., F.R.C.S.
}

"The Epistle to the Reader" from Wiseman's " Severall Chirurgical Treatises," London, Anno Dom. I676.

"He will then wish, that all other Practisers had done what I have in this Treatise, viz. recommended their Observations, both successful and unsuccessful, thereby increasing knowledge in our Profession, and leaving Sea-marks for the discovery of such Rocks as they themselves have split upon before. For my part, I have done it faithfully, and thought it no disgrace to let the world see where I failed of success, that those that come after me may learn what to avoid; there being more of instructiveness often in an unfortunate case than in a fortunate one; and more ingenuity in confessing such misfortunes which are incident to mankind, and which have attended all my Brethren as well as myself, and will attend thee also, Reader, in spight of all thy care and diligence, if thou undertake the imployment. Thou wilt also learn one necessary piece of Humility, viz. not to trust too much on thy own judgment, especially in difficult cases; but to think fit to seek the advice of other Physicians or Chirurgeons, whose long experience hath enabled them to assist thee in preventing the Accidents and encourage thee to go on in the work, or forewarn thee of danger. After thou hast thus defended thyself from the censure of Rashness, proceed boldly and let thy sincerity in thy acting be thy warrant to hope for God's blessing on thy endeavours; and if these papers prove any advantage to thee in them, remember with kindness the Labours of

“May 24, I676.”

$$
\text { “Thy Friend and Servant }
$$

$$
\text { "RICHARD WISEMAN. }
$$

* Reprinted by permission of the Editor of the West African Medical Journal. 


\section{FIVE CASES OF STRICTURE OF THE RECTUM}

The cases of stricture of the rectum, about to be discussed, occurred in Nigeria. One was a male European, three were female natives of Nigeria, and one was a female native of Liberia. Before directing attention to a discussion of some of the problems presented, the cases may usefully be considered seriatim.

\section{CASE I}

E. J., Male, æt. 46, European, Government official, admitted to European Hospital on August I9th, I927, under the care of my colleague Mr. A. Blair Aitken.

Complaint.-Irregular diarrhœa, passage of blood and mucus during four days prior to admission, abdominal discomfort for about nine and a half months, pain referred occasionally to upper abdomen, more recently associated with bowel irregularity, and pain in lower abdomen and hips, loss of weight, 2 stones in eight months.

Clinical Examination.-Marked pallor and wasting.

Chest.-Negative.

Abdomen.-Appreciable degree of splenic enlargement, right kidney ptotic, no definite enlargement of liver.

Rectum.-Per anum, finger fails to detect anything definite. On sigmoidoscopic examination, an ulcerating stricture of bowel $I_{5} \mathrm{~cm}$. from anus, appearances suggestive of carcinoma.

Blood.-Hæmoglobin 6o per cent. to 70 per cent. No malarial parasites.

Differential count.-

Per cent.

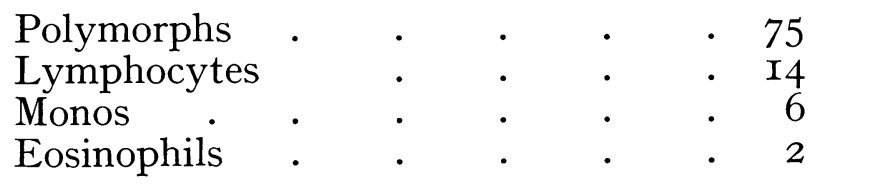

Stool.-Fæcal stained blood and mucus. Cellular débris. No entamœbæ or helmonth ova seen.

I saw this patient with $\mathrm{Mr}$. Aitken and concurred in the diagnosis of carcinoma recti. The patient was boarded and invalided home, the prognosis being regarded as extremely grave.

About six months later, much to my surprise, this patient walked into the consulting room at the European 


\section{BRITISH JOURNAL OF VENEREAL DISEASES}

Hospital, looking very fit. His history was that he had been seen by a specialist on his arrival in London, who had evidently made the same diagnosis of carcinoma, and sent him home to his native town of Norwich as inoperable. His family doctor had the prescience to have a blood Wassermann done, and also a stool examination. The Wassermann was positive and the stools were found to contain Entamœba histolytica. Antisyphilitic measures were instituted and emetin injections given as well, and the rectal condition cleared up completely.

On sigmoidoscopic examination, no evidence of the former condition could be detected, the mucosa was perfectly smooth, the wall mobile, and there was no evidence of any narrowing of the bowel. The fæces were negative for entamœbæ, but the blood Wassermann was still positive. The patient had put on weight and expressed himself as feeling perfectly fit. A course of twelve intravenous injections of $0.6 \mathrm{gm}$. of neosalvarsan and also twejve intramuscular injections of bismuth was given, and a subsequent Wassermann proved negative.

\section{Discussion}

(I) Clinically, the most obvious diagnosis was that of carcinoma recti, but other conditions should have been considered. The fact that the patient was ill, and the consequent desire to get him home to England as soon as possible by the boat sailing soon after his admission to hospital, may be pled in excuse for what might appear as inadequate consideration of other possibilities.

(2) Wassermann blood examinations ought to be part of routine hospital examination. Had this been done, antisyphilitic treatment would in all probability have been instituted, with, perhaps, the happy result deferred until his arrival in Norwich.

(3) The case points the moral of frequent stool examinations. Several stool examinations are usually done in all such cases, but the combination of clinical signs and symptoms, and the seeming necessity for immediate invaliding probably accounted for only one examination being made.

(4) Was this a case of syphilitic stricture of the rectum occurring during amœbic dysentery, or was it a case of dysenteric stricture in a syphilitic subject? The discus- 


\section{FIVE CASES OF STRICTURE OF THE RECTUM}

sion of this point will be deferred until the conclusion of this paper.

\section{CASE 2}

Mrs. H., Female, æt. 42, African, native of Liberia, first seen on December 2nd, I929.

Complaint.-Pain and swelling in perineal region of about eighteen months' duration, had been unable to sit down for twelve months, had been "opened " in Liberia fourteen times.

Previous Relevant History.-Had severe dysentery in I9I9, type unknown. One healthy child now aged about 20 years, subsequent miscarriages.

Clinical Examination.-Marked cachexia.

Chest.-Negative.

Abdomen.-No hepatic or splenic enlargement, slight tenderness in left iliac fossa. A sinus discharging blood and pus on each side of the anus about half an inch distant, scars of previous incisions and much perineal tenderness and swelling.

Rectum.-Digital examination painful, at about Io $\mathrm{cm}$. distance from anus a stricture almost blocking the lumen. Examination under chloroform with the sigmoidoscope revealed an ulcerating stricture of the bowel, bleeding easily and having the appearance of carcinoma. A small piece of tissue was removed for microscopic examination.

Biopsy Report.-Non-malignant.

Urine.-Negative.

Stool.-Blood and mucus, no cellular exudate, no amœbæ or ova.

Blood.-Hæmoglobin 40 per cent. (Tallqvist). No parasites. Differential count that of a secondary anæmia. Wassermann strongly positive.

Presumptive Diagnosis.-Syphilitic stricture of the rectum.

Treatment.-Antiluetic measures by neosalvarsan and bismuth. As the fistulæ seemed to reach too high on the bowel above the stricture for ordinary surgical measures, on December I2th, I929, a small left iliac colotomy was done to prevent fæcal flow over the ulcerated portion of the rectum, and to allow of the latter being washed out. In two weeks the fistulæ were soundly healed, the ulceration had vanished, the rectal mucosa had become smooth and healthy, and the finger could be easily passed through 


\section{BRITISH JOURNAL OF VENEREAL DISEASES}

the region where the stricture had been. The change in the patient was remarkable, she put on weight, ate avidly, her feebleness and cachexia disappeared, she seemed perfectly cured, and she was quite able to sit down without discomfort, a fact which gave her very great satisfaction. On January 3rd, I930, the colotomy opening was excised and an end-to-end anastomosis made, with a perfect result. Seven intravenous injections of neosalvarsan and a like number of intramuscular injections of bismuth were given, and a month after the colotomy wound had healed the patient returned to her native country seemingly perfectly healed and in good condition.

\section{Discussion}

(I) Warned by the experience of the previous case, a biopsy and a blood Wassermann were done in this patient.

(2) The colotomy undoubtedly contributed to the remarkable healing of the fistulæ and the ulcerated stricture. It appears to be a method of treating fistulæ which open high up in the rectal wall, which is worth consideration.

(3) Was this a case of syphilitic stricture of the rectum or a dysenteric stricture in a syphilitic subject?

\section{CASE 3}

C., female, æt. about 25, African, native of Onitsha, first seen March 4th, I930.

Complaint.-Pain and swelling in perineal region, with a discharging opening at side of anus.

No previous history of any kind obtainable, condition has been present for over a year; no children.

Clinical Examination.-General examination, negative.

On the right side of the anus, about I inch distant, a small opening was present which admitted a probe for a distance of slightly over Io $\mathrm{cm}$. On introducing the finger to find out if the probe entered the bowel, an obstruction was found at about $10 \mathrm{~cm}$. distance from the anus. Sigmoidoscopic examination revealed an ulcerating stricture of the bowel.

Stool.-Blood, mucus and pus, no amœbæ or ova, no cellular exudate. 


\section{FIVE CASES OF STRICTURE OF THE RECTUM}

Blood.-No parasites. Wassermann strongly positive. Urine.-Negative.

Presumptive Diagnosis.-Syphilitic stricture of the rectum.

Treatment.-As in the previous case, a colotomy was done, and active antiluetic measures adopted.

The fistula closed in about two weeks' time, the ulceration in the rectum disappeared, and the stricture could be easily passed by the sigmoidoscopic tube. The general appearance of the patient appeared to be very much improved. The colotomy was closed in the usual manner at the expiry of six weeks and the patient returned to her native town in good condition.

\section{Discussion}

(I) A presumptive diagnosis of syphilitic stricture was made. The age of the patient did not rule out malignant disease, because carcinoma of the rectum does occur at an early age, earlier than that of this patient.

(2) No history of dysentery was obtainable, but histories are difficult to obtain, and are often unreliable in the uneducated African. There was no evidence of active dysentery, unless the ulceration and stricture be regarded as such.

(3) Ulcerative colitis of unknown origin is a possibility. Tuberculosis may be ruled out in view of the rapid recovery.

(4) Schistosomiasis may be ruled out as no ova were found in the stool, and the sigmoidoscopic appearances were not characteristic of that disease. The rapid recovery under antiluetic measures again negatives this diagnosis.

(5) Was this a case of syphilitic stricture of the rectum, a dysenteric condition which cleared up under the general measures employed, or an ulcerative colitis, either of the latter being present with a coincident syphilis ?

\section{CASE 4}

A., female, æt. about 30, African, native of Warri, first seen February 6th, I930.

Complaint.-Pain in vagina and passage of fæces per vaginam. 


\section{BRITISH JOURNAL OF VENEREAL DISEASES}

Condition has been present for over a year, no previous history of any illness, no history of dysentery; married, one child aged seven years.

General Condition.-Very cachectic.

Clinical Examination.-General examination negative.

Vaginal Examination.-Situated just within the introitus, on the posterior vaginal wall was an ulcer about the size of a five-shilling piece. Near the upper part of this ulcer, a fistula into the rectum was present.

Rectal Examination.-The examining finger encountered an obstruction about Io $\mathrm{cm}$. from the anal opening. In the centre of the obstruction was an opening barely admitting the tip of the finger. Sigmoidoscopically, a funnel-shaped ulcerating stricture was seen.

Blood.-Hæmoglobin about 40 per cent. (Tallqvist). No parasites. Differential count that of a secondary anæmia. Wassermann strongly positive.

Stool.-Blood, mucus and pus. No amœbæ, no cellular exudate.

Diagnosis.-Dysenteric or syphilitic stricture of the rectum with recto-vaginal fistula.

Treatment.-The vaginal ulcer was cauterised by the electric cautery. A colotomy was done, as in the previous two patients, and the rectum washed out from above. When the vaginal ulcer had soundly healed, a plastic operation was done and the fistula successfully closed. Antiluetic treatment by salvarsan and bismuth was given, seven intravenous injections of the former $(0.6 \mathrm{gm}$.$) and$ seven of the latter intramuscularly, each injection equivalent to $3 \mathrm{c}$. gm. of the metal. Rapid improvement took place in the general condition of the patient, she lost her cachexia and put on weight. The rectal condition cleared up slowly.

The colotomy opening, after six months, was successfully closed. She is now very well. The stricture is dilated as far as the finger can reach, but above this level narrowing of the lumen persists. The mucosa is still somewhat injected, but there is no sign of ulceration and the patient has easy and regular motions. It is proposed to dilate the remaining part of the stricture carefully and gradually.

This patient also had a course of seven emetin injections and her stools are now normal and negative for amœbæ. 


\section{FIVE CASES OF STRICTURE OF THE RECTUM}

\section{Discussion}

(I) The result in this patient ruled out malignant disease.

(2) Tuberculosis may be ruled out for the same reason.

(3) Ulcerative colitis of unknown origin is a possibility, but the clearing up of the condition is rather against this.

(4) Schistosomiasis may be ruled out as no ova were found, and the appearances were not characteristic of that disease.

(5) Was this a case of syphilitic stricture of the rectum, a dysenteric condition which cleared up under the general measures employed, or an ulcerative colitis, either of the latter being present with a coincident syphilis?

\section{CASE 5}

I., female, æt. about 30, African, native of Warri, first seen April 2nd, I930.

Complaint.-Pain in vagina and passage of fæces per vaginam.

Condition has been present for about a year, no children, no history of previous illness.

General Condition.-Anæmic and toxic-looking.

Clinical Examination.-General examination negative, small hernia in right epigastric region, reducible.

Ulceration of posterior vaginal wall, about the size of a shilling, smaller ulcer near external meatus opening on posterior vaginal wall into rectum about $I$ inch within introitus. Condylomata round anus.

Rectal Examination.-The examining finger encountered a narrowing of the lumen about Io $\mathrm{cm}$. from the anus. The stricture admitted the tip of the finger and bled easily. Sigmoidoscopically, an ulcerating stricture.

Blood.-Hæmoglobin about 60 per cent. (Tallqvist). No parasites. Differential count that of secondary anæmia. Wassermann strongly positive.

Stool.-Pus, blood and mucus, no ova, no amœbæ.

Urine.-Negative.

Diagnosis.-Syphilis, Ducrey infection, rectal stricture (? origin) and recto-vaginal fistula.

Treatment.-Ulcers in vagina cauterised with the electric cautery, condylomata snipped off and the bases cauterised. Stricture dilated and antiluetic treatment with salvarsan and bismuth instituted. 


\section{BRITISH JOURNAL OF VENEREAL DISEASES}

During the course of the treatment the patient developed a liver abscess and active entamœba histolytica were found in her stool. The antiluetic treatment was suspended and a series of emetin injections, seven in number, each of I grain was given. The liver abscess cleared up completely. After eight injections of neosalvarsan intravenously and eight intramuscular of bismuth, the rectal condition cleared up completely.

The mucosa became quite smooth and there was no difficulty in defæcation. The ulcers in the vagina healed and the condylomata disappeared.

An attempt was made to rectify the recto-vaginal fistula by a plastic operation but this has not been successful and will require to be done again.

\section{Discussion}

(I) The case is interesting because, though no amœbæ were found at first in the stool, the patient actually developed a liver abscess, and amœbæ were found later whilst she was under treatment by salvarsan.

(2) Active syphilis was undoubtedly present and it is natural to presume that the rectal condition was due to this infection. The results of treatment point in this direction. This case had no adventitious treatment in the way of a colotomy, but she had emetin and it might be argued that the condition was one of dysenteric stricture in a syphilitic subject.

\section{General Discussion}

This series of five cases of rectal stricture bears out the observation that stricture in this region is more common in women than in men. It is difficult to account for this sex incidence. Jonathan Hutchinson suggests that the preponderance in the female may be due to parturition, difficult and prolonged labour causing damage to the rectum from pressure. Two only of the women in this series had borne children, one twenty and the other seven years before the onset of the rectal condition. Lockhart Mummery classifies stricture of the rectum as follows :-

(I) Congenital stricture, found in infants at the junction of the proctodæum and hind gut.

(2) Spasmodic, found, e.g., after an operation or as the 


\section{FIVE CASES OF STRICTURE OF THE RECTUM}

result of irritation or stimulation from the presence of a tumour such as an adenoma.

(3) Fibrous stricture, the result of operation, trauma, sepsis, caustic injections and parturition.

(4) Syphilitic stricture.

(5) Dysenteric.

(6) Stricture of the rectum due to malignant disease.

(7) French authors record a gonococcal stricture similar to that found in the male urethra (Quervain).

The differential diagnosis of those five cases presents a very interesting problem. In the African cases the condition might be attributed to yaws, but no visceral lesions have been described in that disease.

(Vide Manson's "Tropical Diseases," 1 Castellani and Chalmers' "Manual of Tropical Medicine," 2 and Byam and Archibald's "The Practice of Medicine in the Tropics." 3

The diagnosis would appear to lie between syphilis and dysentery, between syphilis in a dysenteric subject or dysentery in a syphilitic subject.

A brief survey of the available literature reveals a curious divergence of opinion. Non-specialist writers, medical and surgical, regard syphilitic stricture of the rectum as of fairly common occurrence.

Ouervain ${ }^{4}$ says, "In females from adolescence to middle age syphilis or gonorrhœa is, under certain conditions, the most probable cause."

Fletcher (Byam and Archibald ${ }^{3}$ ) writes, " Gummatous ulceration of the rectum and stricture following syphilis are commonly mistaken for dysentery. This error can be avoided by making a practice of examining the rectum in every case with symptoms of intractable dysentery."

Most authorities attribute proctitis to syphilis but some to gonorrhœa, and women are the main sufferers.

Richard Cabot ${ }^{5}$ is doubtful if he has ever seen an undoubted stricture of the rectum of syphilitic origin.

Proctologists and syphilologists are very sceptical that such a thing as syphilitic stricture of the rectum exists.

Lockhart Mummery ${ }^{6}$ who is probably the greatest British authority on diseases of the rectum says, "At one time most strictures of the rectum were supposed to be the result of syphilis, and this is generally stated as a common cause in surgical text-books. While I am 


\section{BRITISH JOURNAL OF VENEREAL DISEASES}

not in a position to deny that syphilis may be a cause of rectal stricture, personally I have never met with a case of syphilis of the rectum (excluding, of course, condyloma of the anus and chancre) and at St. Mark's Hospital there is no reliable record of a case of tertiary syphilis of the rectum or of a syphilitic stricture. Considering the very large number of cases of rectal disease, both rare and otherwise, that have passed through the hospital, one would expect that if syphilitic stricture occurred we should have met with several cases. I have been told by surgeons practising in India that syphilitic strictures among the natives are not infrequently met with. If syphilitic stricture does occur, it should easily be proved; but so far, no evidence that can be considered satisfactory has been brought forward to prove it. The fact that a patient suffering from rectal stricture has a history of previous syphilis is of no value. It is well known that antisyphilitic treatment does no good in cases of rectal stricture. It certainly cannot be taken as proved that syphilis is a cause of rectal stricture."

Bensaude ${ }^{7}$ says that he has never seen in the rectum or sigmoid, gummata or undoubted syphilitic ulceration though he has seen ulcerations in syphilitics with a positive Wassermann reaction, which disappeared under antisyphilitic treatment. (Note.-What kind of ulcerations were those ?) On two occasions he has seen an acute proctitis, the lumen of the rectum being surrounded by easily-bleeding vegetations, a biopsy excluded cancer and tuberculosis, the Wassermann was positive and specific treatment rapidly cleared up the lesions. He figures a case (P1. XII, Fig. 3) of an ulcerative growth in the rectum which simulated carcinoma in its appearance but cleared up completely under antisyphilitic treatment. In the figure referred to, if the ulcerated condition were continued completely round the circumference of the bowel, thus diminishing considerably the calibre, it would give a fairly approximate idea of the sigmoidoscopic appearances seen in the five cases described above. Bensaude also figures an ulcer of the rectum, or rather anal canal, " probably cicatrised gumma in a woman suffering from syphilis and tabes" (Pl. XII., Fig. 4). He also figures (Pl. XIII., Figs. I and 2) two inflammatory strictures of the rectum in syphilitic patients.

The syphilologists are almost entirely of the same 


\section{FIVE CASES OF STRICTURE OF THE RECTUM}

opinion as the proctologists that rectal syphilis is an extremely rare condition.

Jonathan Hutchinson ${ }^{8}$ with all his vast experience was doubtful if he had ever seen an undoubted case.

Stokes ${ }^{9}$ is of the same opinion. He quotes Buie of the Mayo Clinic. "In reviewing 258 cases of rectal stricture seen in the Mayo Clinic from I9I2 to I922, Buie found fifty-five patients who had had syphilis. During six years of this period, syphilitic cases were reviewed by the syphilologist and treatment carried out in most cases with signally disappointing results." Stokes discusses one case of stricture of the rectum in a syphilitic " misdiagnosed as syphilitic stricture." $\mathrm{He}$ refers to the favourable effect of salvarsan compounds on amœbic infections and insists that deductions in favour of a diagnosis of intestinal syphilis should not be made because of successful results.

Harrison, ${ }^{10}$ however, holds exactly the opposite opinion of the two authorities quoted above. "Stricture of the rectum is a common result of syphilitic ulceration." Fournier (the great French syphilologist) described a form of syphiloma of the rectum in which the submucous tissues are infiltrated and stricture results without any ulceration.

In the five cases described above, one had no history of dysentery, but as already pointed out, little reliance can be placed on this history; one had a history of dysentery of unknown type ten years prior to her coming for treatment, but with an ulcerating stricture there was no evidence of active dysentery ; and in the other three active E. histolytica were found. Dysenteric stricture, both amœbic and bacillary, is described in the text-books on tropical medicine. I have never recognised a case of amœbic stricture of the rectum, and the cases of bacillary stricture I have seen have all been in very acute or neglected cases, post-mortem, and the strictures were in the colon. The sigmoidoscopic appearances in all of the cases were not at all suggestive of either amœbic or bacillary dysentery.

The reintegration of structure, especially in Case I, makes it difficult to believe that those cases were dysenteric. It has to be granted that in three of the cases the issues are confused by the presence of active amœbæ and the administration of emetin. With respect to the 


\section{BRITISH JOURNAL OF VENEREAL DISEASES}

influence of salvarsan on amœbic infections, referred to by Stokes, Mr. Aitken and I have tried out the effect of salvarsan in obstinate amœbiasis, over a period of some years, without obtaining any appreciable favourable results. In this connection it is interesting to note that in Case 5 a liver abscess developed while the patient was under treatment with salvarsan.

The appearances of the lesions and the rapid and complete return to normal under antisyphilitic treatment aided it may be by the other measures employed, are in favour of syphilis. It is difficult to reconcile this diagnosis with the experience of authors like Mummery and Stokes. A possible explanation might be that in England and America dysentery is rare, whilst in the tropics it is common, and dysentery may be the predisposing condition.

\section{REFERENCES}

(I) Manson's “ Tropical Diseases," edited by Philip Manson-Bahr (I929).

(2) Castellani and Chalmers (Igrg): "Manual of Tropical Medicine."

(3) Byam and Archibald (I92I): "The Practice of Medicine in the Tropics," Vol. II., p. I29r.

(4) Quervain : " Surgical Diagnosis," Vol. I., p. 489.

(5) "Massachussetts Hospital Case Records," edited by R. CABOT, in the New England Medical Journal (I928 or I929? quoted from memory).

(6) Lockhart Mummery : "Disease of the Rectum and Anus."

(7) Bensaude, R. (I926) : "Traite d'Endoscopie, Sigmoidoscopie." Paris.

(8) Jonathan Hutchinson : "Syphilis."

(9) STOKes: " Modern Clinical Syphilology."

(Io) Harrison, L. W. : " The Diagnosis and Treatment of Venereal Diseases in General Practice." 